\title{
(2) OPEN ACCESS \\ Effectiveness of ENDS, NRT and medication for smoking cessation among cigarette-only users: a longitudinal analysis of PATH Study wave 3 (2015- 2016) and 4 (2016-2017), adult data
}

\author{
Bekir Kaplan ๑ , ${ }^{1}$ Panagis Galiatsatos $\odot,{ }^{2}$ Alison Breland $\odot{ }^{3}$ \\ Thomas Eissenberg $\odot{ }^{3}$ Joanna E Cohen ${ }^{1}{ }^{1}$
}

${ }^{1}$ Department of Health, Behavior and Society, Institute for Global Tobacco Control, Johns Hopkins University Bloomberg School of Public Health, Baltimore, Maryland, USA

${ }^{2}$ Division of Pulmonary \& Critical Care Medicine, Tobacco Treatment Clinic, Johns Hopkins Medicine School of Medicine, Baltimore, Maryland, USA ${ }^{3}$ Department of Psychology, Center for the Study of Tobacco Products, Virginia Commonwealth University, Richmond, Virginia, USA

\section{Correspondence to}

Dr Bekir Kaplan, Department of Health, Behavior and Society, Institute for Global Tobacco Control, Johns Hopkins University Bloomberg School of Public Health, Baltimore, MD 21205, USA; bkaplan9@jhu.edu

Received 21 December 2020 Accepted 20 August 2021

\section{ABSTRACT}

Background Research is inconclusive on the effectiveness of electronic nicotine delivery systems (ENDS) as cigarette cessation aids compared with nicotine replacement therapy (NRT) or non-NRT medication. This study compared the cigarette cessation rates for ENDS, NRT and non-NRT medication.

Method Population Assessment of Tobacco and Health Study wave 3 cigarette-only users who used ENDS, NRT or non-NRT medication (varenicline and bupropion) to quit smoking between wave 3 and 4 were included. 'Cessation' was defined as being a former cigarette smoker in wave 4. $\chi^{2}$, logistic regression, and a sensitivity analysis with Bayes factor assessed the association between quitting smoking and method used. Results Among 6794 cigarette-only users, 532 used ENDS ( $n=75)$, NRT ( $n=289)$, non-NRT medication ( $n=68)$, or a combination of NRT and non-NRT medication $(n=100)$ to quit smoking between wave 3 and 4 . The percentages of quitting smoking among those who used ENDS, NRT, non-NRT medication, and a combination of NRT and non-NRT medication were $16.2 \%(n=14)$, $16.1 \%(n=47), 17.7 \%(n=13)$, and $14.8 \%(n=12)$, respectively $(p=0.97)$. None of the cigarette-only users who used ENDS to quit smoking became ENDS-only users in wave $4 ; 37.6 \%$ became dual users of ENDS and cigarettes.

Conclusion No differences were found when cessation rates of ENDS, NRT or non-NRT medication were compared. Given uncertainty about the long-term health effect of ENDS and the likelihood of becoming dual users, people who smoke and need assistance quitting should be encouraged to use current Food and Drug Administration-approved cessation methods until more effective methods are developed.

\section{INTRODUCTION}

People who smoke can benefit from cigarette cessation regardless of their biological age. ${ }^{1}$ Smoking prevalence has declined from $42 \%$ to $13.7 \%$ since the first Surgeon General's report on smoking and health, and since 2002, there have been more former smokers in the USA than current smokers. ${ }^{1}$ However, the tobacco product landscape has been changing in the USA, especially after the introduction of electronic nicotine delivery systems (ENDS). ${ }^{2}$ Among US adults, cigarette smoking prevalence reached a historically low level $(13.7 \% ; 34.2$ million) in 2018, however, ENDS use increased from $2.8 \%$ to $3.2 \%$ for adults and from $11.7 \%$ to $20.8 \%$ for youth during $2017-2018 .^{34}$ In 2019 , ENDS use prevalence reached $4.5 \%$ among adults in the USA. ${ }^{5}$

Most US adults who smoke want to quit smoking cigarettes ${ }^{6}$ and $29.0 \%$ of people who used cigarettes and made a quit attempt in 2015 reported that they used medication to quit smoking. ${ }^{6}$ Several studies have found that some adults also use ENDS to quit or reduce cigarette smoking. ${ }^{7-9}$ However, research is inconclusive on the effectiveness of ENDS as cigarette cessation aids. ${ }^{10-25}$ For example, a randomised controlled trial (RCT) among smokers motivated to quit and who sought cessation services in the UK concluded that the 1-year cigarette abstinence rate was $18 \%$ for the ENDS group and 9.9\% for the nicotine replacement therapy (NRT) group (Relative Risk: 1.83, 95\% CI: 1.30 to 2.58 ), when behavioural support accompanied both products. ${ }^{10}$ In addition, a recent review found that for every 100 adult smokers using nicotine ENDS to stop smoking (6-month abstinence), 10 might successfully stop, compared with only 6 of 100 people using NRT or nicotine-free ENDS, or 4 of 100 people having no support or behavioural support only. ${ }^{11}$ A recent Cochrane Review that included 56 RCTs and randomised cross-over trials reported that ENDS with nicotine increase quit rates compared with ENDS without nicotine and compared with NRT, with moderate certainty evidence. ${ }^{12}$ Moreover, a positive relationship between ENDS use and smoking cessation has also been reported in several studies with other methods such as meta-analysis, ${ }^{13}$ cross-sectional ${ }^{14-17}$ and longitudinal analyses. ${ }^{18-22}$ In contrast, several longitudinal studies ${ }^{723-26}$ found no difference in cigarette cessation (1-year abstinence) between ENDS users and non-users. Furthermore, two meta-analyses ${ }^{27} 28$ that included studies with RCT, cohort and cross-sectional designs reported that a significant reduction in cigarette cessation was associated with ENDS use. Given the inconclusive findings regarding the effectiveness of ENDS as a smoking-cessation aid, ${ }^{29}$ the US Surgeon General's 2020 report on smoking cessation recommended that randomised clinical trials and large-scale observational studies with long-term follow-ups will be critical to better understand the impact of ENDS on cessation. ${ }^{1}$

The aim of this study is to compare the cessation rate among those who used ENDS, NRT, and 
non-nicotine medication as a cessation aid among the Population Assessment of Tobacco and Health (PATH) Study wave 3 adult cigarette-only users who used these methods between wave 3 (2015-2016) and 4 (2016-2017).

\section{METHOD}

\section{Data source}

The PATH Study is an ongoing, nationally representative, longitudinal cohort study of adults and youth in the USA. This study included adult (aged 18 years and older) respondents from wave 3 (2015-2016) and wave 4 (2016-2017) of the PATH Study. ${ }^{30}$ PATH collects information about various tobacco products including cigarettes and ENDS. In addition, PATH Study also collects information about tobacco dependence, cessation, perceptions of risk and harm, and demographic information. ${ }^{3031}$ Information on the sampling procedures can be found in the PATH User Guide. ${ }^{30}$

\section{Study participants}

This study included wave 3 established cigarette-only users who used ENDS, NRT, non-NRT medication (varenicline and bupropion), or a combination of NRT/medication as a cessation aid between wave 3 and 4 . Established cigarette-only users in wave $3(n=6794)$ were defined as adults who have smoked at least 100 cigarettes in their lifetime, and currently smoke every day or some days. Participants who used ENDS to quit smoking stated in wave 4 that they used 'E-cigarettes or other electronic nicotine products' in the past 12 months to quit cigarettes. NRT or medication users responded 'yes' to the questions about using those products in the past 12 months in wave 4 . In order to compare the effectiveness of ENDS and NRT/medication, participants who used a combination of ENDS/NRT $(n=18)$, ENDS/ medication $(n=6)$, and ENDS/NRT/medication $(n=10)$ were excluded from the analysis. In this study, cessation was defined as being a former cigarette smoker in wave 4 . Former smokers were defined as 'wave 4 adult respondents who had smoked at least 100 cigarettes in their lifetime and had not smoked them within the past 12 months or who do not currently smoke at all. The main outcome of this study is becoming a former smoker between wave 3 and 4; that is, a current established cigarette smoker in wave 3 but not currently smoking at all in wave 4.'

\section{Covariates}

The following covariates were used to control for potential confounding: age (18-24; 25-34; 35-44; 45+ years); sex (male; female); race/ethnicity (Non-Hispanic white; NonHispanic black; Hispanic; other); education (less than high school/General Educational Development (GED); high school graduate; beyond high school); household income per year $(<\$ 50$ 000; $\$ \geq 50$ 000), marital status (married; widowed; never married), relying on friend or family support for cigarette quit attempt (yes; no), living with a person who smokes (yes; no), motivation to quit, and cigarette dependence. ${ }^{32}$

Motivation to quit in wave 3 was measured with the following question: 'Overall, on a scale from 1 to 10 where 1 is not at all interested and 10 is extremely interested, how interested are you in quitting cigarettes?'

Eleven Wisconsin Inventory of Smoking Dependence Motives (WISDM) items in wave 3 with response options of 1 (Not true of me at all) to 5 (Extremely true of me) were included to measure cigarette dependence. ${ }^{32}$ Cigarette dependence was the average score of these 11 WISDM items and ranged from 1 to 5 .

\section{Statistical analysis}

All analyses were performed using STATA V.15.1 (Statacorp, College Station, Texas, USA). The PATH Study population weights were used to adjust for the complex study design including oversampling and non-response. Fay's method, a variant of balanced repeated replication method, was used to form replicative weights in variance estimation in all analyses. The Fay coefficient was specified at the value of 0.30 as recommended by the PATH Study. ${ }^{30}$ The weights produce estimates that are representative of the US non-institutionalised, civilian population aged 18 years and older adjusting for non-response from wave 3. Unweighted counts, weighted percentages and means with SEs were presented in the tables. Further information on the weighting procedure can be obtained from the PATH Study Public-Use Files. ${ }^{30}$

Weighted frequency distributions and $\chi^{2}$ tests were used to examine the association between covariates and cigarette cessation status. T-tests were used to assess the mean difference in motivation to quit and cigarette dependence between quitters and non-quitters. In a logistic regression model, the association between quitting smoking and the methods (ENDS, NRT or medication) used was estimated controlling for covariates. All tests were two-sided with significance level set at 5\%.

\section{RESULTS}

The analytical sample of this study included 532 cigarette-only users who used ENDS, NRT, or medication to quit smoking between wave 3 and 4: 75 used ENDS only, 289 NRT only, 68 non-NRT medication only, and 100 used a combination of NRT and non-NRT medication (table 1). Among these 532 cigaretteonly users: $326(54.6 \%)$ were female, 320 (63.3\%) were aged 45 years and over, $376(74.0 \%)$ were non-Hispanic white, 282 $(51.7 \%)$ had beyond high school education, 355 (67.5\%) had less than \$50 000 annual income, 208 (40.2\%) were married, $211(38.2 \%)$ relied on friend/family support, and $242(44.6 \%)$ lived with a person who smokes. The average motivation to quit and cigarette dependence scores were $8.3(\mathrm{SE}=0.1)$ and 3.2 $(\mathrm{SE}=0.1)$, respectively (table 1$)$.

Overall, 16.1\% $(n=86)$ quit smoking in wave 4 (table 2$)$. The percentages of quitting smoking among those who used ENDS, NRT, non-NRT medication, and a combination of NRT and nonNRT medication were $16.2 \%(n=14), 16.1 \%(n=47), 17.7 \%$ $(n=13)$, and $14.8 \%(n=12)$, respectively $(p=0.97)$. These differences remained non-significant in the logistic regression model (table 2). As a sensitivity analysis, we ran the logistic regression model with the Bayes factor to understand the effect of low sample size on statistical significance; there was no significant difference between ENDS and NRT, medication and NRT+medication in the model with the Bayes factor (data not shown).

In total, 192 cigarette-only users in wave 3 used ENDS to quit smoking with or without other methods and none of them became ENDS-only users in wave $4 ; 37.6 \%(n=71)$ became dual users of both cigarettes and ENDS, 52.8\% $(n=100)$ remained as cigarette-only users and $9.6 \%(n=21)$ became non-users of any tobacco product in wave 4 (data not shown). Among 6794 cigarette-only users in wave 3 , the percentage of quitting smoking was $5.3 \%(n=267)$ among those who used neither ENDS nor NRT, nor non-NRT medication (data not shown).

Among participants aged $25-34$ years, $22.3 \%(n=19)$ became former users in wave 4 , while among participants aged 45 years and older, 14.2\% $(n=44)$ became former smokers $(p=0.31)$. The OR for quitting smoking in wave 4 among participants aged 25-34 years was 3.42 (95\% CI: 1.27 to 9.21) compared with 


\begin{tabular}{|c|c|}
\hline & n (\%) \\
\hline \multicolumn{2}{|l|}{ Sex } \\
\hline Male & $206(45.4)$ \\
\hline Female & $326(54.6)$ \\
\hline \multicolumn{2}{|l|}{ Age (years) } \\
\hline $18-24$ & $26(3.1)$ \\
\hline $25-34$ & $93(16.2)$ \\
\hline $35-44$ & $93(17.4)$ \\
\hline$\geq 45$ & $320(63.3)$ \\
\hline \multicolumn{2}{|l|}{ Race/ethnicity } \\
\hline Non-Hispanic white & $376(74.0)$ \\
\hline Non-Hispanic black & $80(13.9)$ \\
\hline Hispanic & $41(7.4)$ \\
\hline Other & $35(4.7)$ \\
\hline \multicolumn{2}{|l|}{ Education level } \\
\hline Less than high school/GED & $141(25.9)$ \\
\hline High school graduate & $108(22.4)$ \\
\hline Beyond high school & $282(51.7)$ \\
\hline \multicolumn{2}{|l|}{ Income (\$) } \\
\hline$<50000$ & $355(67.5)$ \\
\hline$\geq 50000$ & $150(32.5)$ \\
\hline \multicolumn{2}{|l|}{ Marital status } \\
\hline Married & $208(40.2)$ \\
\hline Widowed & $192(37.4)$ \\
\hline Never married & $127(22.4)$ \\
\hline \multicolumn{2}{|c|}{ Relying on friend/family support to quit } \\
\hline No & $285(56.2)$ \\
\hline Yes & $246(43.8)$ \\
\hline \multicolumn{2}{|l|}{ Living with smokers } \\
\hline No & $195(55.4)$ \\
\hline Yes & $242(44.6)$ \\
\hline \multicolumn{2}{|c|}{$\begin{array}{l}\text { Used quitting method (among } 532 \text { cigarette-only users in } \\
\text { wave 3) }\end{array}$} \\
\hline ENDS & $75(12.3)$ \\
\hline NRT & $289(58.5)$ \\
\hline Medication & $68(11.8)$ \\
\hline \multirow[t]{2}{*}{ NRT+medication } & $100(17.4)$ \\
\hline & Mean (SE) \\
\hline Motivation to quit cigarettes & $8.3(0.1)$ \\
\hline Cigarette dependence in wave 3 & $3.2(0.1)$ \\
\hline Total & $532(100.0)$ \\
\hline
\end{tabular}

participants aged 45 years and over, after adjustment for sex, race/ethnicity, education, income, marital status, friend/family support, living with a person who smokes, motivation to quit and cigarette dependence (table 2).

The cigarette dependence score of $2.95(\mathrm{SE}=0.12)$ for participants who became former smokers in wave 4 was significantly lower than the score of 3.25 ( $\mathrm{SE}=0.07)$ for participants who did not quit smoking $(p=0.02)$. However, this was not significant after controlling for other covariates in the logistic regression model (adjusted OR: $0.82,95 \%$ CI: 0.58 to 1.17 ) (table 2). The association between cigarette dependence and quitting smoking was not significant once heaviness of smoking index was used as dependence measure in the regression model (data not shown).

Sex, race/ethnicity, education, income, marital status, friend/ family support, living with a person who smokes and motivation to quit were not significantly associated with quitting smoking (table 2).

\section{DISCUSSION}

The current study compared the cessation rates of ENDS, NRT, non-NRT medication, and a combination of NRT/non-NRT medication for cigarette cessation and found no difference in cessation rates of those methods to quit smoking in a nationally representative cohort.

This finding is consistent with two recently published longitudinal studies that compared the effectiveness of ENDS and approved cessation methods using PATH Study data. Chen et $a l^{23}$ selected a subsample in wave 2 (2014-2015) who had tried to quit smoking at least once by wave 3 (2015-2016), and successfully quit at wave 4 (2016-2017). They reported that the cessation rate among those who used ENDS to help them quit was not different from pharmaceutical cessation aids. Pierce et $a l^{24}$ used a similar method but with wave 1 (2013-2014), wave 2 (2014-2015), and wave 3 (2015-2016) data and reported that use of ENDS compared with approved cessation methods or no products showed similar abstinence rates 1-2 years later. The current study confirms these longitudinal studies from the PATH data and reports no superiority between ENDS and evidencebased cessation methods for cigarette cessation. On the other hand, Glasser et $a l^{21}$ examined the effect of frequent and consistent ENDS use on cigarette cessation among people who used ENDS compared with those who did not use ENDS to help them quit cigarettes and found that consistent and frequent ENDS use over time was associated with cigarette smoking cessation among adults in the USA. Berry et $a l^{20}$ and Azagba et $a l^{22}$ also reported similar findings using PATH Study wave 1 and wave 2 data. However, the current study reported that none of the participants who used ENDS with an intention to quit smoking became ENDS-only users, whereas nearly $40 \%$ of them became dual users which is consistent with prior literature that ENDS have a potential to be used as a supplement to rather than a replacement for cigarettes. ${ }^{33}$ Participants who used ENDS with an intention to quit smoking are likely introducing more toxicants and nicotine from the added use of ENDS which contain carbonyl compounds, ${ }^{2}$ volatile organic compounds ${ }^{2}$ and metals ${ }^{34}$ that are potentially toxic to the respiratory and cardiovascular systems and raise concern about the harmful health consequences of multi-tobacco product use in the long term; given the health risks of ENDS and lack of superiority over Food and Drug Administration (FDA)-approved methods, the clinical guidance at this time should continue to recommend the medication. Besides, consistent with previous literature, despite cigarette cessation rates of these methods are low in this study, the likelihood of quitting smoking doubled among those who used these methods compared with those who used none of them. Thus, people who smoke should be encouraged to use approved cessation methods to reduce health risks of tobacco use and increase the likelihood of quitting cigarettes.

The findings of this study are also consistent with several other longitudinal studies ${ }^{725}$ about the effectiveness of ENDS for cigarette cessation. In a prospective cohort study, it was reported that ENDS use did not help adult participants quit at rates higher than participants who did not use these products at 12 -month follow-up. ${ }^{26}$ In the International Tobacco Control Four-Country Survey, cigarette cessation did not differ between ENDS users and non-users. ${ }^{6}$ In another longitudinal study, ENDS use was not followed by greater quitting 1 year later. ${ }^{25}$ Taking the results of these studies into account, there is growing 
Table 2 Sociodemographic characteristics by quitting cigarettes in wave 4

\begin{tabular}{|c|c|c|c|c|c|c|}
\hline \multirow[b]{3}{*}{ Characteristics } & \multicolumn{4}{|c|}{ Quitting cigarettes } & \multirow[b]{3}{*}{ P value* } & \multirow[b]{3}{*}{ aOR $(95 \% \mathrm{Cl})$} \\
\hline & \multicolumn{2}{|l|}{ Yes } & \multicolumn{2}{|l|}{ No } & & \\
\hline & $\mathrm{n}$ & $\%$ & $\mathrm{n}$ & $\%$ & & \\
\hline \multicolumn{7}{|l|}{ Sex } \\
\hline Male & 33 & 15.1 & 173 & 84.9 & \multirow[t]{2}{*}{0.576} & 1 (Ref) \\
\hline Female & 53 & 16.9 & 273 & 83.1 & & 1.03 (0.48 to 2.19$)$ \\
\hline \multicolumn{7}{|l|}{ Age (years) } \\
\hline$\geq 45$ & 44 & 14.2 & 276 & 85.8 & \multirow[t]{4}{*}{0.31} & 1 (Ref) \\
\hline $35-44$ & 17 & 16.7 & 76 & 83.3 & & $1.82(0.73$ to 4.59$)$ \\
\hline $25-34$ & 19 & 22.3 & 74 & 77.7 & & $3.42(1.27$ to 9.21$)$ \\
\hline $18-24$ & 6 & 17.9 & 20 & 82.1 & & 2.85 (0.49 to 16.6$)$ \\
\hline \multicolumn{7}{|l|}{ Race/ethnicity } \\
\hline Non-Hispanic white & 64 & 16.5 & 312 & 83.5 & \multirow[t]{3}{*}{0.861} & 1 (Ref) \\
\hline Non-Hispanic black & 12 & 13.8 & 68 & 86.2 & & 1.32 (0.49 to 3.52$)$ \\
\hline Other & 10 & 15.9 & 66 & 84.1 & & 1.24 (0.35 to 4.32$)$ \\
\hline \multicolumn{7}{|l|}{ Education level } \\
\hline Less than high school/GED & 21 & 16.3 & 120 & 83.7 & \multirow[t]{3}{*}{0.583} & 1 (Ref) \\
\hline High school graduate & 12 & 12.5 & 96 & 87.5 & & $2.16(0.51$ to 9.19$)$ \\
\hline Beyond high school & 53 & 17.5 & 229 & 82.5 & & $2.19(0.70$ to 6.84$)$ \\
\hline \multicolumn{7}{|l|}{ Income $(\$)$} \\
\hline$<50000$ & 61 & 18.1 & 294 & 81.9 & \multirow[t]{2}{*}{0.093} & 1 (Ref) \\
\hline$\geq 50000$ & 19 & 11.1 & 131 & 88.9 & & $0.65(0.23$ to 1.86$)$ \\
\hline \multicolumn{7}{|l|}{ Marital status } \\
\hline Married & 35 & 18.9 & 173 & 81.1 & \multirow[t]{3}{*}{0.373} & 1 (Ref) \\
\hline Widowed & 29 & 14.2 & 163 & 85.8 & & $0.95(0.42$ to 2.14$)$ \\
\hline Never married & 21 & 13.8 & 106 & 86.2 & & $0.54(0.17$ to 1.73$)$ \\
\hline \multicolumn{7}{|c|}{ Relying on friend/family support to quit } \\
\hline No & 43 & 15.3 & 242 & 84.7 & \multirow[t]{2}{*}{0.584} & 1 (Ref) \\
\hline Yes & 43 & 17.1 & 1203 & 82.9 & & $0.97(0.44$ to 2.14$)$ \\
\hline \multicolumn{7}{|l|}{ Living with smokers } \\
\hline No & 37 & 18.3 & 158 & 81.7 & \multirow[t]{2}{*}{0.361} & 1 (Ref) \\
\hline Yes & 33 & 14.6 & 209 & 85.4 & & $0.58(0.28$ to 1.21$)$ \\
\hline \multicolumn{7}{|l|}{ Used quitting method } \\
\hline ENDS & 14 & 16.2 & 61 & 83.8 & \multirow[t]{4}{*}{0.976} & 1 (Ref) \\
\hline NRT & 47 & 16.1 & 242 & 83.9 & & $1.54(0.50$ to 4.72$)$ \\
\hline Medication & 13 & 17.7 & 55 & 82.3 & & $0.87(0.15$ to 5.05$)$ \\
\hline \multirow[t]{2}{*}{ NRT+medication } & 12 & 14.8 & 88 & 85.2 & & $1.72(0.39$ to 7.61$)$ \\
\hline & Mean (SE) & & Mean (SE) & & & \\
\hline Motivation to quit cigarettes & $8.00(0.36)$ & & $8.32(0.14)$ & & 0.435 & $1.01(0.85$ to 1.20$)$ \\
\hline Cigarette dependence in wave 3 & $2.95(0.12)$ & & $3.25(0.07)$ & & 0.021 & $0.82(0.58$ to 1.17$)$ \\
\hline Total & 86 & 16.1 & 446 & 83.9 & & \\
\hline
\end{tabular}

${ }^{*} \chi^{2}$ test (bivariate association).

$\mathrm{aOR}$, adjusted OR; ENDS, electronic nicotine delivery system; NRT, nicotine replacement therapy; Ref, reference.

evidence that ENDS use does not seem to help quitting cigarettes at higher rates compared with approved methods and cigarette cessation success might depend on other factors such as age and dependence level, rather than the methods used for cessation. In this study, young age was the only significant factor associated with smoking cessation. One explanation could be that young smokers have been using cigarettes for a shorter period of time compared with those older than 45 years. In addition, young smokers' cigarette use behaviour could be less established and stable.

Importantly, even national, population-based, longitudinal surveys such as PATH may not be the ideal studies in which to assess whether or not ENDS are effective cessation products, as they do not have the same controls over elements such as product type, nicotine concentration, and power setting, or the same measurement measures (such as uses per day or similar) as in traditional RCTs. Conversely, these population-based studies provide valuable information about the external validity/generalisability (or 'real-world' effects) of ENDS in the population in the absence of the controls in RCTs. Furthermore, real-world studies are especially important considering that ENDS are sold as commercial products and not FDA-approved therapeutic medications. Thus, there is no clinical guidance for users to follow as would accompany a medication and there is a lower likelihood that ENDS would be used in a manner that is 'effective' for quitting.

This study has several limitations. First, cigarette, ENDS, NRT, and non-NRT medication use were self-reported by participants and thus there could have been misclassification regarding tobacco use or methods to quit cigarettes. Second, the 
What this paper adds

- Some adults who smoke cigarettes use electronic nicotine delivery systems (ENDS) with an intention to quit cigarette smoking. However, research is inconclusive on the effectiveness of ENDS as cigarette cessation aids.

- This study compares the cessation rates of participants who smoke cigarettes only and used ENDS, nicotine replacement therapy (NRT), and non-NRT medication as cessation aids among adult respondents of the Population Assessment of Tobacco and Health Study who used these methods between wave 3 (2015-2016) and 4 (2016-2017).

- No difference in the effectiveness of ENDS, NRT or non-NRT medication for cigarette cessation was observed.

- None of the participants who used ENDS with an intention to quit smoking became ENDS-only users, whereas nearly $40 \%$ of them became dual users.

analyses were limited to cigarette-only users who used ENDS, NRT, and non-NRT medication to quit smoking between wave 3 and 4 which excluded more than 90\% of wave 3 participants who smoke cigarettes exclusively. Reduced sample size might partly explain the general lack of significant factors. Third, the follow-up time between wave 3 (2015-2016) and wave 4 (20162017 ) in this study was relatively short. Therefore, assessing the sustainability of cigarette cessation after the follow-up time was not possible. Fourth, 6.6\% $(n=35)$ of the former smokers in the wave 4 reported that they used cigarettes in the last 3 months. However, the results of this study remained the same when the analyses were repeated without those participants. Fifth, the frequency of use of NRT and non-NRT medication, duration of use, type of NRT and adherence of the medication guidelines were also not available for this sample. Further, it was not possible to assess the type of ENDS product used, nicotine delivery from an ENDS product or the frequency of ENDS use in this sample; these factors likely affect ENDS' potential effectiveness as a cessation aid. As the ENDS market evolves, it is possible that more people who smoke will use products that are better able to deliver nicotine while minimising toxicant delivery. The frequency of use of NRT and non-NRT medication was also not available for this sample. The non-significance in this paper might be a result of low sample size or a heterogeneous group of ENDS products. We were unable to control for the type of ENDS product, however, we performed an analysis with the Bayes factor to examine whether the non-significant results are due to low sample size. We were not able to use the 'svy' command while performing the analysis with the Bayes factor because STATA does not have this capability. Despite these limitations, comparing the effectiveness of ENDS, NRT and non-NRT medication using nationally representative longitudinal study data that portray the products that people who smoke choose to use is the strength of this study.

This study contributes to the current literature that the effectiveness of ENDS on cigarette cessation is not different than FDA-approved methods among people who are current established cigarette users. People who smoke should be encouraged to quit at an earlier age and use FDA-approved cessation methods such as NRT or non-NRT medication to quit cigarette smoking to reduce health risks associated with ENDS use $\mathrm{e}^{35} 36$ and/or dual use of cigarette and ENDS. ${ }^{37} 38$ Given the low cessation rates of these methods, there is a need for approaches/interventions with higher cessation rates to reduce cigarette smoking prevalence. Future studies with information on the exact type of ENDS products used, frequency of use and a longer follow-up time are needed to better compare the effectiveness of ENDS, NRT or medication for successful cigarette quitting.

Contributors JEC and BK first conceived the study question, while all authors contributed to the development of the analysis plan and manuscript. BK reviewed the literature and wrote the original manuscript text. BK was primarily responsible for data analysis, under the mentorship of JEC. All authors edited the manuscript text. JEC supervised the work and all authors revised the manuscript critically for important intellectual content. All authors reviewed the manuscript and have approved the final version.

Funding This research was supported by the National Institute on Drug Abuse of the National Institutes of Health under Award Number U54DA036105 and the Center for Tobacco Products of the US Food and Drug Administration.

Disclaimer The content is solely the responsibility of the authors and does not necessarily represent the official views of the National Institutes of Health or the Food and Drug Administration.

Competing interests TE is a paid consultant in litigation against the tobacco industry and also the electronic cigarette industry and is named on one patent for a device that measures the puffing behaviour of electronic cigarette users and on another patent for a smartphone app that determines electronic cigarette device and liquid characteristics. The other coauthors declare no conflict of interests.

Patient consent for publication Not required.

Provenance and peer review Not commissioned; externally peer reviewed.

Data availability statement Data are available in a public, open access repository.

Open access This is an open access article distributed in accordance with the Creative Commons Attribution Non Commercial (CC BY-NC 4.0) license, which permits others to distribute, remix, adapt, build upon this work non-commercially, and license their derivative works on different terms, provided the original work is properly cited, appropriate credit is given, any changes made indicated, and the use is non-commercial. See: http://creativecommons.org/licenses/by-nc/4.0/.

\section{ORCID iDs}

Bekir Kaplan http://orcid.org/0000-0003-2497-4742

Panagis Galiatsatos http://orcid.org/0000-0001-8309-0985

Alison Breland http://orcid.org/0000-0001-8949-2395

Thomas Eissenberg http://orcid.org/0000-0002-8277-5437

Joanna E Cohen http://orcid.org/0000-0002-3869-3637

\section{REFERENCES}

1 U.S. Department of Health and Human Services. Smoking cessation. a report of the surgeon general, 2020. Available: https://www.hhs.gov/sites/default/files/2020cessation-sgr-full-report.pdf [Accessed 30 Aug 2020].

2 U.S. Department of Health and Human Services. E-cigarette use among youth and young adults. a report of the surgeon general, 2016. Available: https://e-cigarettes. surgeongeneral.gov/documents/2016_SGR_Full_Report_non- 508.pdf [Accessed 30 Aug 2020].

3 Creamer MR, Wang TW, Babb S, et al. Tobacco product use and cessation indicators among adults - United States, 2018. MMWR Morb Mortal Wkly Rep 2019:68:1013-9.

4 Cullen KA, Ambrose BK, Gentzke AS, et al. Notes from the field: use of electronic cigarettes and any tobacco product among middle and high school students - United States, 2011-2018. MMWR Morb Mortal Wkly Rep 2018;67:1276-7.

5 Cornelius ME, Wang TW, Jamal A, et al. Tobacco product use among adults - United States, 2019. MMWR Morb Mortal Wkly Rep 2020;69:1736-42.

6 Babb S, Malarcher A, Schauer G, et al. Quitting smoking among adults_-United States, 2000-2015. MMWR Morb Mortal Wkly Rep 2017;65:1457-64.

7 Adkison SE, O'Connor RJ, Bansal-Travers M, et al. Electronic nicotine delivery systems: international tobacco control four-country survey. Am J Prev Med 2013;44:207-15.

8 Nicksic NE, Snell LM, Barnes AJ. Reasons to use e-cigarettes among adults and youth in the population assessment of tobacco and health (path) study. Addict Behav 2019;93:93-9

9 Berg CJ, Barr DB, Stratton E, et al. Attitudes toward e-cigarettes, reasons for initiating e-cigarette use, and changes in smoking behavior after initiation: a pilot longitudinal study of regular cigarette smokers. Open J Prev Med 2014;4:789-800.

10 Hajek P, Phillips-Waller A, Przulj D, et al. A randomized trial of e-cigarettes versus nicotine-replacement therapy. N Engl J Med 2019;380:629-37.

11 Hartmann-Boyce J, McRobbie H, Lindson N, et al. Electronic cigarettes for smoking cessation. Cochrane Database Syst Rev 2020;10:CD010216.

12 Hartmann-Boyce J, McRobbie H, Lindson N, Butler AR, et al. Electronic cigarettes for smoking cessation. Cochrane Database Syst Rev 2021;4:CD010216. 
13 Rahman MA, Hann N, Wilson A, et al. E-cigarettes and smoking cessation: evidence from a systematic review and meta-analysis. PLoS One 2015;10:e0122544.

14 Siegel MB, Tanwar KL, Wood KS. Electronic cigarettes as a smoking-cessation: tool results from an online survey. Am J Prev Med 2011;40:472-5.

15 Zhu S-H, Zhuang Y-L, Wong S, et al. E-cigarette use and associated changes in population smoking cessation: evidence from US current population surveys. BMJ 2017;358:j3262-8.

16 Giovenco DP, Delnevo CD. Prevalence of population smoking cessation by electronic cigarette use status in a national sample of recent smokers. Addict Behav 2018;76:129-34.

17 Coleman BN, Rostron B, Johnson SE, et al. Electronic cigarette use among US adults in the population assessment of tobacco and health (path) study, 2013-2014. Tob Control 2017; 26:e117-26.

18 Etter J-F, Bullen C. A longitudinal study of electronic cigarette users. Addict Behav 2014:39:491-4.

19 Brose LS, Hitchman SC, Brown J, et al. Is the use of electronic cigarettes while smoking associated with smoking cessation attempts, cessation and reduced cigarette consumption? a survey with a 1-year follow-up. Addiction 2015:110:1160-8.

20 Berry KM, Reynolds LM, Collins JM, et al. E-cigarette initiation and associated changes in smoking cessation and reduction: the population assessment of tobacco and health study, 2013-2015. Tob Control 2019;28:42-9.

21 Glasser AM, Vojjala M, Cantrell J, et al. Patterns of e-cigarette use and subsequent cigarette smoking cessation over 2 years (2013/2014-2015/2016) in the population assessment of tobacco and health study. Nicotine Tob Res 2021:23:669-77.

22 Azagba S, Qeadan F, Shan L, et al. E-cigarette use and transition in adult smoking frequency: a longitudinal study. Am J Prev Med 2020;59:367-76.

23 Chen R, Pierce JP, Leas EC. E-cigarette use to aid long-term smoking cessation in the US: prospective evidence from the path cohort study. Am J Epidemiol.

24 Pierce JP, Benmarhnia T, Chen R, et al. Role of e-cigarettes and pharmacotherapy during attempts to quit cigarette smoking: the path study 2013-16. PLoS One 2020:15:e0237938.

25 Grana RA, Popova L, Ling PM. A longitudinal analysis of electronic cigarette use and smoking cessation. JAMA Intern Med 2014:174:812-4.
26 Weaver SR, Huang J, Pechacek TF, et al. Are electronic nicotine delivery systems helping cigarette smokers quit? evidence from a prospective cohort study of U.S. adult smokers, 2015-2016. PLoS One 2018;13:e0198047.

27 Grana R, Benowitz N, Glantz SA. E-cigarettes: a scientific review. Circulation 2014; 129:1972-86.

28 Kalkhoran S, Glantz SA. E-cigarettes and smoking cessation in real-world and clinical settings: a systematic review and meta-analysis. Lancet Respir Med 2016;4:116-28.

29 National Academies of Sciences, Engineering, and Medicine. Public health consequences of e-cigarettes. Washington, DC: The National Academies Press, 2018.

30 Inter-University Consortium for Political and Social Research (ICPRS), National Addiction \& HIV Data Archive Program. Population assessment of tobacco and health (PATH) study [United States] public-use files (ICPSR 36498), 2019. Available: https://www.icpsr.umich.edu/icpsrweb/NAHDAP/studies/36498/datadocumentation [Accessed 18 May 2019].

31 Hyland A, Ambrose BK, Conway KP, et al. Design and methods of the population assessment of tobacco and health (path) study. Tob Control 2017;26:371-8.

32 Strong DR, Pearson J, Ehlke $S$, et al. Indicators of dependence for different types of tobacco product users: descriptive findings from wave 1 (2013-2014) of the population assessment of tobacco and health (path) study. Drug Alcohol Depend 2017;178:257-66.

33 Kasza KA, Ambrose BK, Conway KP, et al. Tobacco-product use by adults and youths in the United States in 2013 and 2014. N Engl J Med Overseas Ed 2017:376:342-53.

34 Olmedo P, Goessler W, Tanda S, et al. Metal concentrations in e-cigarette liquid and aerosol samples: the contribution of metallic coils. Environ Health Perspect 2018;126:027010.

35 Martinez-Morata I, Sanchez TR, Shimbo D, et al. Electronic cigarette use and blood pressure endpoints: a systematic review. Curr Hypertens Rep 2020;23:2.

36 Osei AD, Mirbolouk M, Orimoloye OA, et al. Association between e-cigarette use and cardiovascular disease among never and current combustible-cigarette smokers. Am J Med 2019;132:949-54.

37 Wang JB, Olgin JE, Nah G, et al. Cigarette and e-cigarette dual use and risk of cardiopulmonary symptoms in the health eHeart study. PLoS One 2018;13:e0198681.

$38 \mathrm{Kim}$ C-Y, Paek Y-J, Seo HG, et al. Dual use of electronic and conventional cigarettes is associated with higher cardiovascular risk factors in Korean men. Sci Rep 2020;10:5612 